\title{
More than science
}

Shaun Sellars continues his series on ethical dilemmas in dentistry which

appears in every second issue of the BDJ.

I'm writing this on the first weekend of May. We're currently still in lockdown, but there are whispers of this easing soon. There continues to be a discussion of when we can all go back to work and how things might have to change for us to work safely. Throughout all of this, the message has been that we will 'follow the science' when considering how we return to routine dentistry. But there's more to consider than just the science, especially when much of that science is uncertain and sometimes contradictory.

Research and 'science' rely on interpretation and are not politically or morally neutral. Furthermore, hard science doesn't lead directly to policy choices.

It is becoming increasingly clear that we're going to have to learn to live with COVID-19 for some time. Equally, the profession is eager to start providing dentistry to patients as soon as is feasible. This desire is driven partly by a want to help patients, and partly by the need to salvage the dental industry before a large number of practices become insolvent.

How do we balance the want to return to practice with the need to keep ourselves, our patients and our communities safe? This question becomes harder to answer as we're not even sure of how much of a risk dentistry is in the age of COVID-19.

As things stand, we're assuming that dentistry is high-risk. This won't be the case forever, and may not even be the case right now, but until the science is in, we need to rely on the precautionary principle. When considering returning to routine dentistry, we need to balance the risks of patients and dental staff contracting

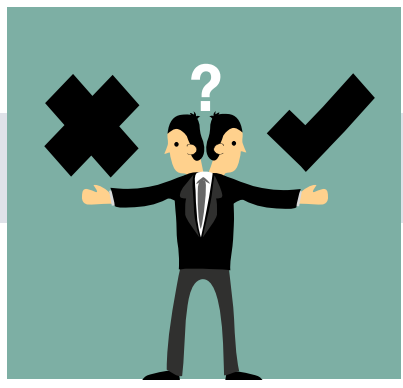

COVID-19, and the risks to patients of suffering pain and dental disease, which requires urgent treatment. There also needs to be a discussion about the financial implications of returning to work.

It is clear that returning to work using FFP3 respirators, enhanced PPE and infection control procedures, and an hour between aerosol-generating procedures, while being the theoretical 'safest' way to proceed, is financially impossible for a large number of practices. It's also unlikely to be required for the vast majority of symptom-free patients.

Similarly, going back to 'normal' using surgical masks, routine PPE and seeing patients on the same schedules as before is currently considered by many to be too risky for patients and dentists alike.

There has to be a complicated and potentially awkward conversation around the point where the risk to patients from their non-COVID-19 disease outweighs their risk from COVID-19. Alongside this conversation is a similar one regarding the economic fall-out of the response to the virus, which may have a longer and more detrimental effect, than the virus itself.

As the science behind the coronavirus outbreak becomes more explicit, the balance of patient risk to benefit becomes more comfortable to define. Still, the final decision will not be based solely on the science. It's based on the moral choices that the science informs.

\section{Working group publishes rapid review for re-opening dental services}

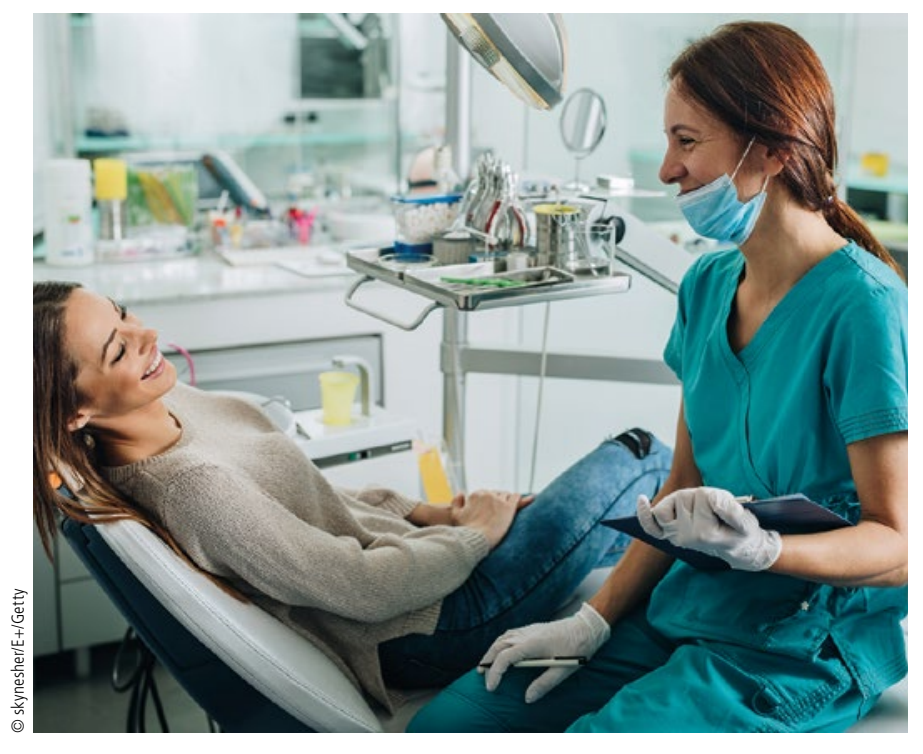

The COVID-19 Dental Services Evidence Review (CoDER) Working Group, a group led by Professors Jan Clarkson and Craig Ramsay, has conducted a rapid review of internationally produced guidance for re-opening dental services. The review has been published in Cochrane Oral Health.

Recommendations for the re-opening of dental services: review of international sources, published 6 May 2020, can be accessed at: https://oralhealth.cochrane.org/news/recommendations-re-openingdental-services-rapid-review-international-sources.

The review, which is subject to revision, collates and summarises recommendations from the various sources identified within five themes relevant to the re-opening of dental services: practice preparation, personal protective equipment, management of the clinical area, dental procedures, and cleaning and disinfection.

The key messages emerging from the review can also be accessed at the link above. A table in the appendices shows what steps each country is taking for restructuring their dentistry amidst the COVID-19 pandemic. 